\title{
Endovascular therapeutic options for the treatment of aortoiliac aneurysms
}

\section{Opções terapêuticas endovasculares para o tratamento dos aneurismas aortoilíacos}

Bernardo Massière ${ }^{1,2}$; Arno von-Ristow ${ }^{1}$; Alberto Vescovi'; Daniel leal ${ }^{1}$; Lea Mirian Barbosa Fonseca².

\begin{abstract}
A B S T R A C T
About $20 \%$ of patients with abdominal aortic aneurysms have associated iliac aneurysms. Distal sealing during the endovascular treatment of aortic-iliac aneurysms is a challenge that has led to the emergence of several technical options to achieve this goal over the years. Internal iliac artery embolization is associated with the risk of ischemic complications, such as gluteal necrosis, lower limb neurological deficit, colonic ischemia, impotence and gluteal claudication. This article summarizes the technical options for endovascular treatment of aortoiliac aneurysms with different approaches to preserving the patency of internal iliac arteries.
\end{abstract}

Keywords: Aortic Aneurysm. Iliac Artery. Endovascular Procedures.

\section{INTRODUCTION}

$T^{1}$ he involvement of common iliac arteries occurs in $20 \%$ of patients with abdominal aortic aneurysms (AAA) and is a challenge to endovascular treatment because it compromises sealing and distal fixation of endoprostheses ${ }^{1}$. Several techniques have been developed to achieve the goal of sealing the aneurysmal sac. However, long-term treatment efficacy is dependent on careful selection². The purpose of this review is to discuss the endovascular techniques for preserving internal iliac artery patency in the treatment of aortoiliac aneurysms (AIA).

\section{Embolization of the internal iliac artery}

Internal iliac artery (IIA) embolization prevents type-2 endoleak, resulting from the IIA retrograde flow into the aneurysm sac. Occlusion coils are implanted in the IIA prior to the implantation of an endoprosthesis to cover its origin and to extend to the external iliac artery $(E \mid A)^{3,4}$. An occluder (nitinol plug) may also be used instead of the coils, with a better cost-effectiveness and a lower incidence of complications due to greater position control during release ${ }^{5}$. Complications of this procedure are due to the ischemic effects of IIA embolization. Gluteal claudication is the dominant symptom, and may manifest with different intensities and eventually regress over time. Its incidence varies from $13 \%$ to $50 \%$ and the risk is lower when the coils are positioned proximally to the IIA bifurcation ${ }^{3,4,6}$.

In the literature, there are other complication reports of IIA embolization, such as sexual dysfunction, neurological deficit, urinary retention, gluteal necrosis and colonic ischemia ${ }^{6,7}$.

\section{Cerclage of the common iliac artery}

Puech-Leo ${ }^{8}$, in 2000, reported treatment of AlAs by adapting the previously described ${ }^{9}$ technique of common iliac artery (CIA) cerclage for the treatment of endoleak in patients undergoing AAA endovascular treatment (Figure 1). Initially, extraperitoneal surgical access to CIA is performed. The artery is dissected cranially at its bifurcation, extending 2 to $3 \mathrm{~cm}$ and two vascular tapes are passed around the vessel with a distance of $1 \mathrm{~cm}$ between them. After completion of the retroperitoneal approach, inguinal incisions are made to expose the femoral arteries. The endoprosthesis is introduced and a forceps is placed at the level

1 - Pontifical University of Rio de Janeiro, CENTERVASC-RIO, Department of Vascular Surgery, Rio de Janeiro State, Brazil. 2 - Federal University of Rio de Janeiro, Department of Radiology, Rio de Janeiro State, Brazil. 


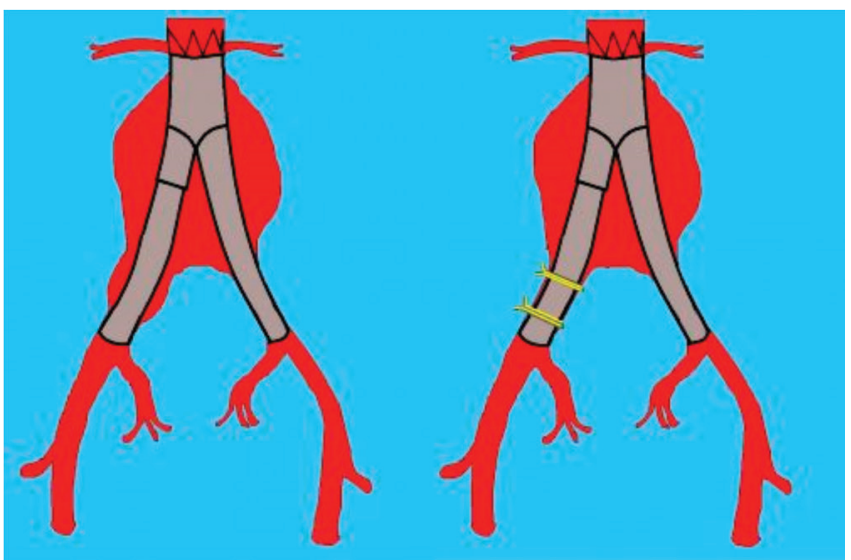

Figure 1. Iliac cerclage technique. Representative scheme of the cerclage technique in the treatment of aortoiliac aneurysms.

of the most caudal vascular tape, to be used as a radiopaque reference to fluoroscopy. After positioning and expanding the device, a balloon catheter of the same diameter as the endoprosthesis is introduced over fluoroscopy and inflated to the caudal end of the endoprosthesis. The two vascular tapes are tied until the resistance promoted by the balloon is perceived. The balloon is then deflated and removed for control angiography ${ }^{8}$.

\section{Iliac branches in bell-bottom}

The bell-bottom technique was originally described with the use of a proximal aortic extension (cuff) selected based on the diameter of the iliac artery and positioned with at least $1 \mathrm{~cm}$ overlap within the distal iliac branch and by at least $1 \mathrm{~cm}$ in an area of the ectasized $\mathrm{CIA}$ (Figure 2A) ${ }^{10}$. The presence of a thrombus in the ectasia segment is a contraindication to this technique. The cuffs described in this configuration are expanded to adapt to the iliac branch, promoting adequate distal sealing in the ectasiated or aneurysmatic CIA. Thereafter, broad-diameter iliac branches specifically developed for this purpose have become available for use in the bell-bottom technique ${ }^{11}$. There is no consensus on the CIA limiting diameter recommended for the use of this technique. A study analyzing common iliac arteries up to $30 \mathrm{~mm}$ in diameter submitted to the implantation of bell-bottom endoprostheses demonstrated a satisfactory long- term outcome (type-1B endoleak in $4 \%$ of cases) ${ }^{11}$. A comparative analysis showed no evolutionary difference between a group of patients with AICs submitted to the implantation of bell-bottom endoprostheses with a diameter between $20 \mathrm{~mm}$ and $22 \mathrm{~mm}$ and a group with a diameter between $24 \mathrm{~mm}$ and $28 \mathrm{~mm}^{12}$. The incidence of type-1B endoleak observed in the literature ranged from 0 to $11 \%^{10-15}$. However, the Mayo Clinic group reports late dilation of CIA affecting up to $86 \%$ of patients ${ }^{10-12,14}$. Nonetheless, some authors relate this late expansion to over-dimensioning greater than 15\% of the endoprostheses implanted in the $\mathrm{CIA}^{16}$, without correlation with adverse effects ${ }^{14}$.

\section{Sandwich}

The sandwich technique for the treatment of aortoiliac aneurysms was initially described by Lobato $^{17}$. This technique consists of the following steps: 1) femoral implantation of a bifurcated stent graft, with position of the contralateral iliac branch $1 \mathrm{~cm}$ cranial to the CIA ostium; 2) IIA catheterization

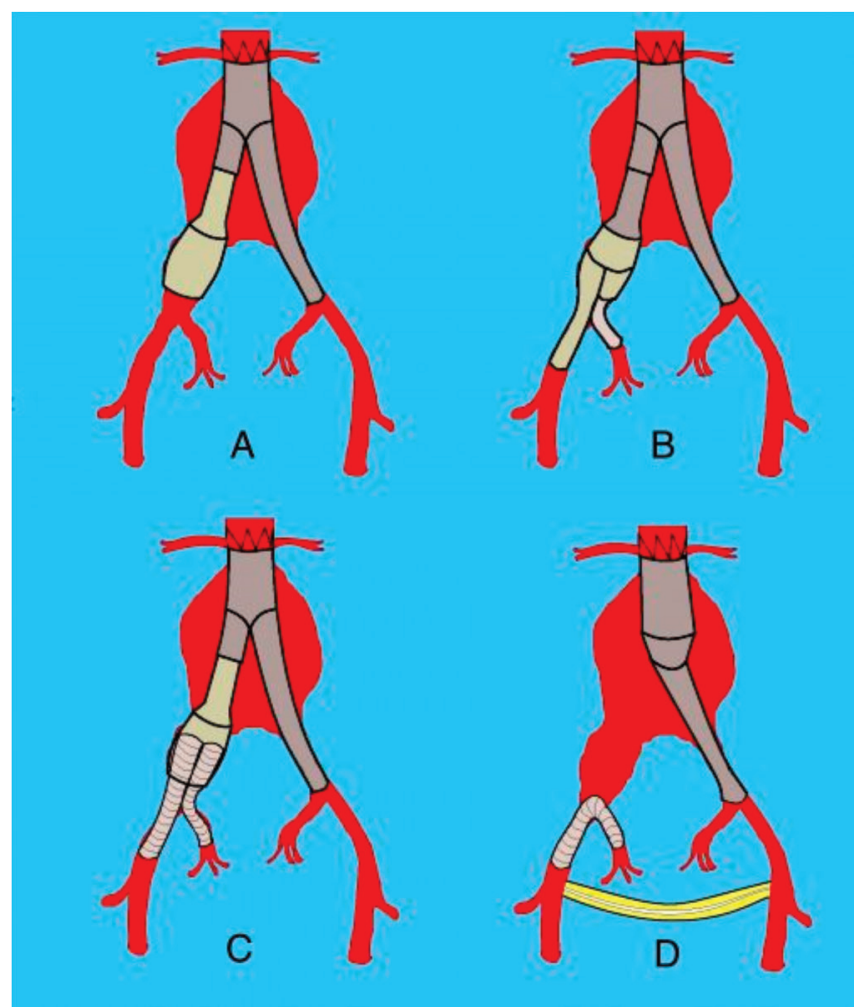

Figure 2. Endovascular techniques for the treatment of aortoiliac aneurysms. A) bell-bottom; B) branched iliac endoprosthesis; C) sandwich; D) retrograde endovascular revascularization of the internal iliac artery. 
through left brachial access; 3) implantation of a coated, self-expanding stent in the IIA, with adequate overlap in the iliac branch, followed by implantation of the iliac branch of the endoprosthesis; 4) Modeling of the iliac branch and expanding the stent using balloon catheters; 5) implantation of the contralateral iliac branch (Figure $2 \mathrm{C})^{18}$. Lobato ${ }^{17}$ indicates overlapping of more than $6 \mathrm{~cm}$ between endoprostheses to minimize the formation of gutters and the risk of leakage. Limitations of this technique include the need to use long iliac endoprostheses, the potential risk of compression of one of the parallel endoprostheses, and the absence of controlled data with a long follow-up period $^{2}$. Despite these considerations, the technique is used in several centers with reports of low prostheses occlusion rates or leaks ${ }^{19-22}$. Lobato describes a series with 40 patients, with an average follow-up time of 12 months, observing $100 \%$ technical success rates, primary patency of $93.8 \%$, and type-3 endoleak (associated with the technique) of $2.5 \%{ }^{23}$.

\section{Branched internal iliac artery endoprosthesis}

The IIA branching technique consists of the implantation of a bifurcated iliac stent combined with a coated stent connecting the latter with IIA. The ZBIS $®$ endoprosthesis is available with external branches in the helical and straight configurations, the latter being the most used. This device is generally combined with an endoprosthesis implanted in the abdominal aorta (Figure 2B) ${ }^{18,24}$. In our country, Massière and von Ristow ${ }^{24}$ developed a bifurcated branched device based on the Apollo platform, and used the Viabahn® connecting stent.

The following morphological criteria are described for the use of the ZBIS device technique: the presence of a non-aneurysmal segment of the EIA of at least $20 \mathrm{~mm}$ in length and a diameter between $8 \mathrm{~mm}$ and $11 \mathrm{~mm}$, with the length of the CIA greater than $50 \mathrm{~mm}$, luminal diameter of the CIA greater than $16 \mathrm{~mm}$ and the presence of a non-aneurysmal segment of the IIA at least $10 \mathrm{~mm}$ in length and with a diameter between $6 \mathrm{~mm}$ and $9 \mathrm{~mm}^{2,18,25}$. Using these criteria, a study of 51 patients undergoing AIAs treatment determined that only $38 \%$ of the patients analyzed fully met the requirements determined by the manufacturer ${ }^{26}$.

Ferreira et $a^{27}$ published a study investigating 47 bifurcated devices implanted in 37 patients with an average follow-up time of 11.6 months. Technical success was obtained in $97.3 \%$ of the cases and a secondary patency rate in 22 months of $85.4 \%$. They observed stent occlusion in five patients (10.6\%), gluteal claudication in one case $(2.7 \%)$ and no endoleaks. The incidence of complications associated with the device, evaluated by the combined incidence of type1endoleak, type-3 endoleak and branch occlusion, varies from $7 \%$ to $13.8 \%$ in the literature. The incidence of gluteal claudication varies from 2.7 to $5.6 \%{ }^{26-31}$. The main limitation to this technique is the anatomical prerequisites necessary for the device implanting ${ }^{32}$.

A meta-analysis analyzing the performance of 236 connection, coated stents in five studies on branched endoprosthesis reported an incidence of occlusion in $6 \%$ of the cases and gluteal claudication in $3.4 \%$, with the main causes being the IIA small diameter, IIA perioperative dissection due to excessive dilation, use of long stents, concomitance of IIA atherosclerotic disease, and compression associated with the use of the helical model branched device. A lower occlusion rate was observed in cases in which the expandable balloon stent was used as a connection stent. However, statistical methods could not be used due to the heterogeneity of the studies ${ }^{31}$.

Until the moment of submission of this article, only initial results of the use of the Excluder ${ }^{\circledR}$ iliac branched endoprosthesis were published ${ }^{32}$

\section{Retrograde endovascular revascularization of the internal iliac artery}

The technique of retrograde endovascular revascularization of the internal iliac artery was initially described by Hoffer et $a^{\beta 3}$. It consists of the implantation of a conical aorto-uni-iliac endoprosthesis, followed by the creation of a femoral-femoral cross-bridge and implantation of a contralateral coated stent, extending from the EIA to the IIA with the objective of preserving pelvic perfusion (Figure 2D). 
Massière et $a^{\beta 4}$ described a series of 21 patients submitted to this technique for the treatment of complex aortoiliac aneurysms, unable of being submitted to another endovascular technique and with a high surgical risk. They used the Viabahn $®$ connecting stent. The mean follow-up time was 52 months, with technical success in all cases, endoleak associated with the connection stent in one patient (4.7\%), type-IB endoleak in one patient $(4.7 \%)$ and occlusion of the coated stent in one case $(4.7 \%)$ in 30 days $^{31}$.

The need for the extra-anatomical bridge constitutes a limitation to this technique due to the risk of infection and thrombosis, being reserved for selected cases. However, no complications associated with cross-bridge were observed and the technique allows the treatment of cases with complex anatomy, offering few anatomical restrictions to its use.

\section{CONCLUSION}

Each one of the various endovascular techniques available for the treatment of aortoiliac aneurysms presents its anatomical limitations. The complexity of these cases requires adequate selection of the technique that will allow the exclusion of the aneurysm, offering lower risk and better outcome in the long term.

\section{R E S U M O}

Cerca de $20 \%$ dos pacientes com aneurismas de aorta abdominal apresentam aneurismas ilíacos associados. A obtenção do selamento distal, durante o tratamento endovascular dos aneurismas aortoilíacos, constitui-se em um desafio que suscitou, ao longo dos anos, o surgimento de diversas opções técnicas para alcançar esse objetivo. A embolização da artéria ilíaca interna é associada ao risco de desenvolvimento de complicações isquêmicas, tais como: necrose glútea, déficit neurológico dos membros inferiores, isquemia colônica, impotência e claudicação glútea. Esse artigo resume as opções técnicas de tratamento endovascular dos aneurismas aortoilíacos com diferentes formas de abordagem de preservação da perviedade das artérias ilíacas internas.

Descritores: Aneurisma Aórtico. Artéria llíaca. Procedimentos Endovasculares.

\section{REFERENCES}

1. Brunkwall J, Hauksson $H$, Bengtsson $H$, Berqqvist D, Takolander E, Bergentz SE. Solitary aneurysms of the iliac arterial system: an estimate of their frequency of occurrence. J Vasc Surg. 1989;10(4):381-4

2. Fatima J, Correa MP, Mendes BC, Oderich GS. Pelvic revascularization during endovascular aortic aneurysm repair. Perspect Vasc Surg Endovasc Ther. 2012;24(2):55-62.

3. Criado FJ, Wilson EP, Velazquez OC, Carpenter JP, Barker C, Wellons E, et al. Safety of coil embolization of the internal iliac artery in endovascular grafting of abdominal aortic aneurysms. J Vasc Surg. 2000;32(4):684-8.

4. Cynamon J, Lerer D, Veith FJ, Taragin BH, Wahl SI, Lautin JL, et al. Hypogastric artery coil embolization prior to endoluminal repair of aneurysms and fistulas: buttock claudication, a recognized but possibly preventable complication. J Vasc Interv Radiol. 2000;11(5):573-7.
5. Vandy F, Criado E, Upchurch GR Jr, Williams DM, Rectenwald J, Eliason J. Transluminal hypogastric artery occlusion with an Amplatzer vascular plug during endovascular aortic aneurysm repair. J Vasc Surg. 2008;48(5):1121-4.

6. Farahmand $P$, Becquemin JP, Desgranges $P$, Allaire E, Marzelle J, Roudot-Thoraval F. Is hypogastric artery embolization during endovascular aortoiliac aneurysm repair (EVAR) innocuous and useful? Eur J Vasc Endovasc Surg. 2008;35(4):429-35.

7. Engelke C, Elford J, Morgan RA, Belli AM. Internal iliac artery embolization with bilateral occlusion before endovascular aortoiliac aneurysm repair-clinical outcome of simultaneous and sequential intervention J Vasc Interv Radiol. 2002;13(7):667-76.

8. Puech-Leao P. Banding of the common iliac artery: an expedient in endoluminal correction of aortoiliac aneurysms. J Vasc Surg. 2000;32(6):1232-4.

9. Chuter TA, Risberg B, Hopkinson BR, Wendt G, Scott RA, Walker PJ, et al. Clinical experience with a 
bifurcated endovascular graft for abdominal aortic aneurysm repair. J Vasc Surg. 1996;24(4):655-66.

10. Karch LA, Hodgson KJ, Mattos MA, Bohannon WT, Ramsey DE, McLafferty RB. Management of ectatic, nonaneurysmal iliac arteries during endoluminal aortic aneurysm repair. J Vasc Surg. 2001;33(2 Suppl):S33-8.

11. Torsello G, Schönefeld E, Osada N, Austermann M, Pennekamp C, Donas KP. Endovascular treatment of common iliac artery aneurysms using the bell-bottom technique: long-term results. J Endovasc Ther. 2010;17(4):504-9.

12. Naughton PA, Park MS, Kheirelseid EA, O'Neill $S M$, Rodriguez HE, Morasch MD, et al. A comparative study of the bell-bottom technique vs hypogastric exclusion for the treatment of aneurysmal extension to the iliac bifurcation. J Vasc Surg. 2012;55(4):956-62.

13. Kritpracha B, Pigott JP, Russell TE, Corbey MJ, Whalen RC, DiSalle RS, et al. Bell-bottom aortoiliac endografts: an alternative that preserves pelvic blood flow. J Vasc Surg. 2002;35(5):874-81.

14. England A, Butterfield JS, McCollum CN, Ashleigh RJ. Endovascular aortic aneurysm repair with the talent stent-graft: outcomes in patients with large iliac arteries. Cardiovasc Intervent Radiol. 2008;31(4):723-7.

15. Alvarez Marcos F, Garcia de la Torre A, Alonso Perez M, Llaneza Coto JM, Camblor Santervas LA, Zanabili Al Sibbai AA, et al. Use of aortic extension cuffs for preserving hypogastric blood flow in endovascular aneurysm repair with aneurysmal involvement of common iliac arteries. Ann Vasc Surg. 2013;27(2):139-45.

16. Kirkwood ML, Saunders A, Jackson BM, Wang GJ, Fairman RM, Woo EY. Aneurysmal iliac arteries do not portend future iliac aneurysmal enlargement after endovascular aneurysm repair for abdominal aortic aneurysm. J Vasc Surg. 2011;53(2):269-73.

17. Lobato AC. Sandwich technique for aortoiliac aneurysms extending to the internal iliac artery or isolated common/internal iliac artery aneurysms: a new endovascular approach to preserve pelvic circulation. J Endovasc Ther. 2011;18(1):106-11.

18. Geisbüsch $P$, Attigah N, Hyhlik-Dürr $A$, Hakimi M, Müller-Eschner M, Böckler D. Decision-making and techniques in hypogastric artery revascularization. J Cardiovasc Surg (Torino). 2013;54(1 Suppl 1):71-9.

19. Friedman SG, Wun H. Hypogastric preservation with Viabahn stent graft during endovascular aneurysm repair. J Vasc Surg. 2011;54(2):504-6.

20. Mosquera Arochena N, Rodríguez Feijoo G, Carballo Fernandez C, Molina Herrero F, Fernandez Lebrato R, Barrios Castro A, et al. Use of modified Sandwich-graft technique to preserve hypogastric artery in EVAR treatment of complex aortic aneurysm anatomy. J Cardiovasc Surg (Torino). 2011;52(5):643-9.

21. Heckenkamp J, Brunkwall J, Luebke T, Aleksic M, Schöndube F, Stojanovic T. Novel chimney-graft technique for preserving hypogastric flow in complex aortoiliac aneurysms. J Cardiovasc Surg (Torino). 2012;53(6):773-6.

22. Yoshida Rde A, Yoshida WB, Kolvenbach R, Vieira PR. Modified "stent-graft sandwich" technique for treatment of isolated common iliac artery aneurysm in patient with Marfan syndrome. Ann Vasc Surg. 2012;26(3):419.e7-9.

23. Lobato AC, Camacho-Lobato L. The sandwich technique to treat complex aortoiliac or isolated iliac aneurysms: results of midterm follow-up. J Vasc Surg. 2013;57(2 Suppl):26S-34S.

24. Massière B, von Ristow A, Cury J, Gress M, Vescovi A, Marques $M$. Internal iliac artery branch stent grafting for aortoiliac aneurysms using the Apollo branched device. Ann Vasc Surg. 2010;24(3):417. e15-8.

25. Physician's pocket reference guide. Zenith ${ }^{\circledR}$ Endovascular Grafts. Queensland, Australia: Cook Medical; 2012. p. 45-50.

26. Karthikesalingam A, Hinchliffe RJ, Malkawi AH, Holt PJ, Loftus IM, Thompson MM. Morphological suitability of patients with aortoiliac aneurysms for endovascular preservation of the internal iliac artery using commercially available iliac branch graft devices. J Endovasc Ther. 2010;17(2):163-71. 
27. Ferreira M, Monteiro M, Lanziotti L. Technical aspects and midterm patency of iliac branched devices. J Vasc Surg. 2010;51(3):545-50.

28. Karthikesalingam A, Hinchliffe RJ, Holt PJ, Boyle JR, Loftus IM, Thompson MM. Endovascular aneurysm repair with preservation of the internal iliac artery using the iliac branch graft device. Eur J Vasc Endovasc Surg. 2010;39(3):285-94.

29. Donas KP, Torsello G, Pitoulias GA, Austermann M, Papadimitriou DK. Surgical versus endovascular repair by iliac branch device of aneurysms involving the iliac bifurcation. J Vasc Surg. 2011;53(5):1223-9.

30. Parlani G, Verzini F, De Rango P, Brambilla D, Coscarella $C$, Ferrer $C$, et al. Long-term results of iliac aneurysm repair with iliac branched endograft: a 5-year experience on 100 consecutive cases. Eur J Vasc Endovasc Surg. 2012;43(3):287-92.

31. Donas KP, Bisdas T, Torsello G, Austermann M. Technical considerations and performance of bridging stent-grafts for iliac side branched devices based on a pooled analysis of single-center experiences. J Endovasc Ther. 2012;19(5):667-71.
32. Ferrer C, De Crescenzo F, Coscarella C, Cao P. Early experience with the Excluder ${ }^{\circledR}$ iliac branch endoprosthesis. J Cardiovasc Surg (Torino). 2014;55(5):679-83.

33. Hoffer EK, Nicholls SC, Fontaine AB, Glickerman DJ, Borsa JJ, Bloch RD. Internal to external iliac artery stent-graft: a new technique for vessel exclusion. J Vasc Interv Radiol. 1999;10(8):1067-73.

34. Massière $B$, von Ristow $A$, Vescovi $A$, Pedron $C$, Fonseca LM. Management of aortoiliac aneurysms by retrograde endovascular hypogastric artery preservation. Vascular. 2014;22(2):116-20.

Received in: 12/07/2016

Accepted for publication: 26/09/2016

Conflict of interest: none.

Source of funding: none.

\section{Mailing address:}

Bernardo Massière

E-mail: bvm200@gmail.com

drbernardo@centervasc.com.br 